\title{
WELCOME TO THE ACM TURING CENTENARY PROGRAM
}

As we celebrate the life of the man who asked whether machines could think, we welcome the ACM Turing Award winners and members of the computing community who have joined together to commemorate this pioneer whose work laid many of the foundations of our discipline.

\section{Alan Turing's wide-ranging interests ranged from} the purely theoretical to the eminently practical. He contributed to our fundamental understanding of what can be computed through the invention of what we now refer to as the Universal Turing Machine. On the practical side, his work on the design of the ACE (Automatic Computing Engine) drew upon his wartime experience at Bletchley Park and blazed trails toward the breakthrough technology of stored-program computing.

The accomplishments of the Turing Award winners represented at this celebration continue to validate the enduring power of Turing's work. This program is organized to reflect facets of Turing's contributions that have placed him in prominence in the history of computing.

Individual speakers will focus on the use of computable reals in successful verification techniques for safety-critical systems; transformational thinking about programming language and computer design; examining computers that engage with the physical world in ways not previously possible; and the future of Lambda Calculus: the smallest universal programming language in the world.

Panelists will discuss a range of topics that reflect connections to Turing and his legacy: personal stories of Turing the man; imagining the future of artificial intelligence; how the Turing machine model shaped Computer Science; and information, data and security in a networked world.

Additional panel discussions include: programming language design legacies and lessons; the extension of Turing's vision of human memory via computer architecture research; how systems research and engineering practices complement and challenge each other; and the impact of algorithmic thinking beyond computation.

Alan Turing's genius has inspired generations of computer scientists and engineers, and it is fitting that his legacy and life should be recognized and celebrated by the community that carries on and extends his work.

VINTON G. CERF

General Chair

ACM TURING CENTENARY CELEBRATION 